\title{
RESEARCH
}

Open Access

\section{Policy transfer processes and renewable energy penetration: a comparative analysis of Peru, Thailand, and Uganda}

Stefan Bößner', Tim Suljada ${ }^{1}$, Francis X. Johnson ${ }^{1 *}$ D, Aina Bruno², Jorge Rodriguez Morales ${ }^{3}$, Mengyin Hu${ }^{4}$, Padmasai Lakshmi Bhamidipati ${ }^{5}$ and James Haselip ${ }^{5}$

\begin{abstract}
Background: Low-carbon technologies must be widely adopted at a large scale to address climate change and enhance access to affordable, reliable and sustainable energy. The uptake of those technologies is often supported by specific policies developed at a national or regional level and those policies, like the technologies themselves, can diffuse from one place to another. This paper sheds some light on this 'policy transfer' and investigates the dynamics, the actors and the processes involved. We illustrate what happens when renewable energy support policies in one country inspire renewable support policies in another country using three case studies in Peru, Thailand and Uganda as examples.
\end{abstract}

Results: Using an adapted version of the policy transfer framework first elaborated by Dolowitz and Marsh (Polit Stud 44:343-57, 1996; Governance 13:5-23, 2000), we describe the policy transfer process in the three case study countries according to several criteria. We find that policy transfer is not a straightforward process where a 'borrower' country simply adopts policies from a 'lender' country, but instead a complex process where many actors - national and international - interact to shape the outcome of the process. And while experiences particularly in the EU as well as international developments have influenced the policy transfer in case study countries significantly, domestic issues also play a key role in shaping the transferred policies and in adapting them to local contexts. Moreover, the policy transfer process is not an one-off event, but a continuous process where iterative learning helps the policies to evolve over time.

Conclusions: Policy transfer is a complex matter, involving many stakeholders during a continuous process over time. The Dolowitz and Marsh framework proved useful to analyse policy transfer and the actors involved although questions for further research remain. For instance, against what kind of criteria should the 'success' of a policy transfer be measured? Moreover, while comparing three illustrative case studies is a first, useful step, having a larger set of case studies and data might enhance our understanding of the details of the processes involved even further.

Keywords: Policy transfer, Policy innovation, Renewable energy, Technology transfer, International cooperation, Socio-technical analysis, Low-carbon technologies

\footnotetext{
* Correspondence: francis.johnson@sei.org

'Stockholm Environment Institute, Stockholm, Sweden

Full list of author information is available at the end of the article
}

(c) The Author(s). 2020 Open Access This article is distributed under the terms of the Creative Commons Attribution 4.0 International License (http://creativecommons.org/licenses/by/4.0/), which permits unrestricted use, distribution, and reproduction in any medium, provided you give appropriate credit to the original author(s) and the source, provide a link to the Creative Commons license, and indicate if changes were made. The Creative Commons Public Domain Dedication waiver (http://creativecommons.org/publicdomain/zero/1.0/) applies to the data made available in this article, unless otherwise stated. 


\section{Introduction}

The global concerns raised by climate change led to the adoption of the Paris Agreement in which parties draft their own national determined contributions (NDCs), a process reflective of differentiated responsibilities and respective capabilities in the light of different national circumstances. Indeed, under the Paris Agreement, developed countries should continue taking the lead by undertaking economy-wide absolute emission reduction targets, but developing countries are also expected to enhance their mitigation efforts [1]. The agreement also calls upon the international community to cooperate in implementing their NDCs under Article 6, the details of which are still being negotiated [2].

Global uptake of Renewable Energy (RE) technologies supports achievement of the NDCs as well as the UN Sustainable Development Goals (SDGs) [3, 4]. International cooperation includes the transfer of technologies and know-how between more industrialised and less industrialised countries, which is a guided and intentional process [5-8]. Other related concepts include 'technology diffusion', which emphasise the spontaneous spreading of technologies by market-forces and 'technology innovation', which emphasises the novelty or improvement of a product or technology [9-12]. While the boundaries of those three concepts are often not clear-cut, the aim of stimulating demand for technologies such as RE in as many regions as possible contributes to global learning curves, thus making these new technologies more costcompetitive and more adaptive to local contexts [13]. The rapid cost reductions experienced for wind and solar power during the past few decades, for example, are the result of market developments in the European Union (EU), China and other regions of rapid growth where enabling policies have been in place for many years $[14,15]$.

Such enabling policies are the focus of this paper. Although technology transfer and diffusion have long been studied, the question of how the policies and institutional arrangements supporting those technologies might 'flow' from one country to another (and how they are adapted to local contexts) only emerged recently in the academic literature (See e.g. [16-22]).

This article describes how knowledge of renewable energy policy spreads (or is transferred) across different countries or regions and how those policies are designed and what institutional setups those policies create in different countries. This framework of policy diffusion (in this paper referred to as policy transfer), is based on the analytical tools and conceptual contributions made by Dolowitz and Marsh [23, 24] on policy transfer analysis, as well as on the complementary literature. It draws from an analysis of three case studies on RE in Uganda, Peru, and Thailand and is structured as follows. Section
2 of the paper reviews briefly the links between institutions, technology change, and policy transfer as a strategy for low-carbon technology deployment. Section 3 provides the overall approach and framework for the comparative analysis. Section 4 includes the results of the analysis and aims to shed some light on how policy transfer operates. The analysis will look at the causes and motivations behind policy transfer, the actors involved in the processes, the object of the transfer, the spatial and temporal scale, the mechanisms, the drivers and barriers observed in the processes, as well as the success or failure and the stages of policymaking in which policy transfer takes place.

The paper contributes to improving the understanding of how technology transfer, as an external intervention, connects with ongoing internal processes and institutional conditions at the national and local level.

The paper focuses particularly on feed-in tariffs and renewable energy auctions as policy instruments to be analysed due to the significance of those instruments in the three case study countries and the prevalence of these instruments among renewable energy policy instruments used in the EU and around the world [25].

\section{Conceptual foundations of policy innovation, policy diffusion and policy transfer}

In order to meet the objectives of the Paris Agreement (PA), fundamental changes in how we produce, distribute and consume goods and services are necessary to allow for rapid decarbonisation [26]. These transformations are often summarised as transition pathways from one system to another, for instance from a carbonintensive economy to a low-carbon one [27]. However, this transformation is subject to various challenges. For instance, new mitigation technologies are initially more expensive than their fossil fuel-based counterparts even though learning curves and constant innovation have made renewable energies cost-competitive in many parts of the world [28]. Moreover, vested interests in preserving high-carbon practices and habits or dominant 'regimes' as they are called in the literature [27, 29, 30] present stumbling blocks on those transition pathways since those regimes often benefit from historic institutional support [29, 31]. In order for new technologies and new practices to successfully challenge those old regimes, it is therefore important to either change the economics of those new technologies (i.e. make them cheaper) or to change the institutional set-up to level the playing field. Here, institutions are understood from a social science perspective namely as the rules, norms, and behaviors that sustain social structures such as religion, family networks or government agencies [32]. For instance, EU power markets, for decades designed around centralised, fossil-fuel-based electricity, will have 
to be adapted to an increasing share of flexible, decentralised renewables production to meet EU emission reduction targets [33, 34]. New institutional set-ups, manifest in a re-arrangement of competencies of actors involved, as well as new policies, will have to be found.

Therefore, besides technological innovation, policy innovation is needed to reflect new realities. For instance, policy mechanisms can shield nascent (or niche) technologies from market forces and allow for experimentation, a process which is often referred to as 'niche management' $[35,36]$. Besides shielding new technologies, policymakers can also take an active role in creating markets for technologies thus providing a demand 'pull' in addition to a technology 'push' [37]. Other strategies involve increased research and development (R\&D) spending in the nascent phase of technology innovation or rendering new, innovative technologies more visible by, for example, adopting informational policies [37].

In that sense, technological innovation cannot be successful without policy innovation. It is worth noting that a successful process of policy innovation will depend largely on the adaptive capacity of the country to absorb, assimilate and harness the knowledge regarding lowcarbon technologies. This 'adaptive efficiency' refers to the willingness and ability of a society to acquire new knowledge, to innovate, to take risks through experimentation, and to eliminate failed political and economic organizations and institutions that produce inefficient or unfair outcomes [38].

Policymakers and other innovation system actors, the prime movers of such institutional setups, have at least two options to adapt institutions to their needs. They can look at past national experiences from similar problems and try to adapt those past experiences to current issues, or they can look beyond their own jurisdiction and see how other policymakers in other countries or regions responded to similar problems [23,39].

This looking beyond national borders is indeed the core of this paper, which investigates what happens when policies spread from one place to another, a process that is somewhat analogous--and/or coincident with--the spread of technologies. Before elaborating on the intellectual framework applied in the case study, it is, however, useful to describe some differentiation in the literature.

\section{Policy transfer}

Policy transfer is commonly defined as when '[...] knowledge about policies, administrative arrangements, institutions and ideas in one political setting (past or present) is used in development of policies, administrative arrangements, institutions and ideas in another political setting' [24]. Often, countries where policies originated are referred to as 'lender' countries while countries adopting the transferred policies are often referred to as 'borrowers' [24]. However, the question of whether and how policies cross jurisdictions is not a new one, and several different, related concepts can be found in literature.

For instance, Rose [39], speaks of 'lesson drawing' which emphasises the voluntary nature of the process ([39], p. 9). Furthermore, lesson-drawing implies a process of prospective evaluation, which not only encompasses the assessment of the policy already being implemented, but also the appraisal of whether this policy can be successfully implemented in the borrower country [39]. Policy convergence, another concept, similarly preoccupied scholars from the early 1990s and tried to answer the question if and why countries become more alike in their governance of societal issues, be it due to elite networks, harmonization of policies or emulation in an ever increasingly connected world [40].

\section{Policy transfer vs. policy diffusion}

Another concept, sometimes used interchangeably with policy transfer, is policy diffusion. Marsh and Dolowitz argue that while policy transfer literature would emphasise agency, policy diffusion literature would emphasise the structural causes (government set ups, economic pressure, media landscape etc.) of policies crossing from one jurisdiction to another [20]. Both strands of literature would have large commonalities as both would identify four methods of policy diffusion/transfer, namely (1) mimicry (to seem more progressive for instance); (2) coercion (think of policies imposed by international lenders on Greece during the financial crisis); (3) learning (lesson drawing from the success or failure elsewhere) and (4) competition (such as lowering taxes and red tape to attract investment) although evidence for some methods remains patchy at best [20].

It is clear from the description above, that all of these concepts - policy diffusion, policy transfer, lessons learning and policy convergence - are strongly interrelated concepts. Some focus on the question of "what" is transferred (policy diffusion) while others are more occupied with the question of why (convergence, lessons learning). All of the concepts offer some explanatory values specific to them, but we chose to base our further analysis on the Dolowitz and Marsh model since it has a strong conceptual foundation and has been developed by iteration, drawing on the range of concepts. Following Dolowitz and Marsh, we will use the term "policy transfer" throughout the following sections.

\section{Analytical framework and comparative analysis of policy transfer}

The comparative analysis of policy transfer developed in this section is structured mainly around the set of analytical and developed by Dolowitz and Marsh [23, 24]. 
This analytical framework, in turn, gathers contributions from the literature in the fields of policy diffusion, policy transfer, and policy convergence as well as from other sources in policy comparative studies and international studies (Rose 2001, [39-43]).

While theoretical reflections about policy transfer investigate how to conceptualise the transfer of policies and institutions from one country to another, the analytical framework elaborated by Dolowitz and Marsh proposes several attributes which make analysing policy transfer more concrete and systematic. The authors suggest that in order to better understand the transfer of policies, one could look first at why policies are transferred and at whether it was a voluntary transfer or a more coercive one. Other criteria to look at is who is involved in the transfer (which stakeholders), and what instrument (policies, entire programmes or lessons) is transferred. Dolowitz and Marsh also suggest to investigate at which level the transfer happens (within a nation, between nations) and to also analyse the constraints of the transfers and the motivations for the transfer (all based on [23]; and [24]).

However, in order to make this framework more flexible to our case study contexts, we chose to both simplify their model to reflect the different socio-economic contexts of the case study countries, but also to enrich it with several attributes to further our understanding of the policy transfer process. The principal expansion we make to the framework is to look at which stage of the policy making cycle [44] policy transfer might happen, a step of analysis not found in Dolowitz and Marsh.

Our analytical framework addresses the key aspects of policy transfer and contains the following categories: "causes and motivations", "actors", "object of transfer", "temporal and spatial scale", "mechanisms of transfer", "drivers and barriers", "policy success or failure" as well as the "policy-making stage" of the policy transfer. Figure 1 provides a graphic representation of our analytical framework. In section 4, each category contains a table showing the specific criteria used in our analysis.

These eight analytical attributes of the policy transfer process were applied to case studies, as discussed in the section below, which also gives an overview of the methods applied and provides some case study context.

\section{Approach, methodology and case study context}

Following the literature review (included in section 2) and development of the initial research, three country case studies were chosen using recent or current policies and institutions that could be compared. The cases identified were in Uganda, Thailand and Peru, based on the following criteria:

- The aim of geographical diversity to help to provide a global perspective;

- Different socio-economic levels, including two middle income (Peru, Thailand) and one low-income country (Uganda) as compared to high-income EU countries;

- Experience with different renewable energy instruments, specifically that renewable energy auctions and feed-in tariffs were considered and/ or used;

- Engagement in international cooperation, including with EU member states, where feed-in tariffs and renewable auctions were common policy instruments; and

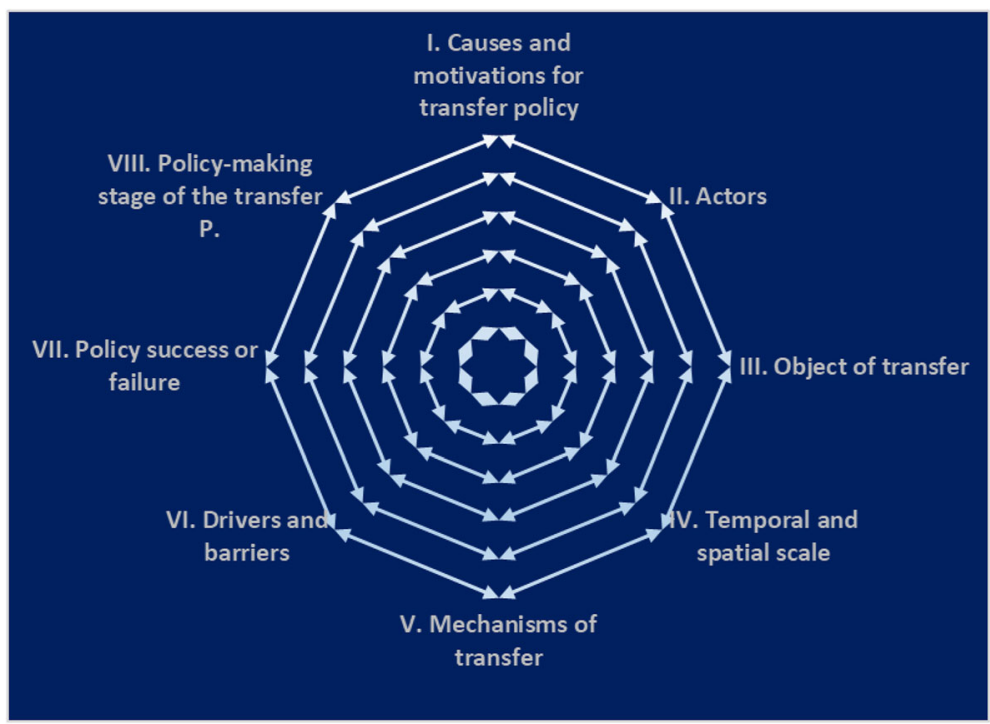

Fig. 1 Analytical framework for policy transfer processes. Source: Authors' elaboration based on Dolowitz and Marsh [23, 24] 
- Participating researchers had some experience in these countries.

The main research questions were then applied to the country cases:

- How is policy transferred from one jurisdiction to the other?

- Which are the important actors that facilitate that transfer?

- How do the policies and institutional arrangements in the "borrower" country differ from the policies and institutional arrangements in the "lender" country?

- Are there discernible differences between the three countries in the way they borrow or receive policies and/or institutions?

Semi-structured stakeholder interviews conducted in the three case study countries are the primary sources for the analysis to address our research questions. Stakeholders in the three case studies included development agencies, academics, development banks, electricity regulatory authorities, and independent consultants. Based on material gathered during those stakeholder engagement processes along with background literature, we analysed the policy transfer process using the adapted Dolowitz and Marsh model in the three case studies. The policy context for the three country cases are introduced briefly below. Where information on case studies came from the literature, sections below will indicate the corresponding papers. Otherwise, sources of information are stakeholder interviews.

\section{Thailand}

Thailand's successful economic growth in recent years did not only drive up emissions [45] but raised concerns of the country's energy security [46] due to the country's increasing energy consumption. Although Thailand still sources its energy needs to $88 \%$ from fossil fuels, the 12th National Economic and Social Development Plan for the period of 2012 to 2027 calls for the country to move towards a low carbon society [47]. Based on those concerns about sustainability but also about energy security, Thailand experimented early with support instruments for renewable energy. In 2007, the so-called "Adder programme" was launched which guaranteed renewable energy producers a top-up of the regular standard tariff. This adder scheme was later replaced by a fixed FiT in 2013 while competitive bidding for FiT contracts was introduced between 2016 and 2017. It was this period and the evolution from the Adder to the FiT programme which was the subject of the analysis focusing on the questions whether policy transfer had taken place, if so, who the important actors were and what institutional arrangements influenced Thai renewables policies. In Thailand, 12 stakeholders were engaged and a series of semi-structured interviews were conducted in April 2017 in Bangkok, Thailand.

\section{Uganda}

Similar to the Thai case study, we looked at the transfer process which occurred when the country designed and implemented a FiT scheme for investment in on-grid RE. This policy was an important step since rural electrification rates were at a low $10 \%$ in 2014 [48]. The elaboration and adoption of Ugandan FiTs can be separated into three different phases with the first one beginning in 2007. Each phase exhibited different institutional arrangements and different engagements with other jurisdictions and international entities. Especially phase II and II (2010-2011 and beyond) saw increasing cooperation with other, nonUgandan actors such as the German Development Bank, the Kreditanstalt für Wiederaufbau (KfW), which led to the adoption of the Global Energy Transfer Feed-in Tariff programme (GET-FiT) which attracted some significant RE investment. In Uganda, semi-structured interviews were conducted with 14 stakeholders ranging from the representative members of energy regulatory authority, bilateral development bank, multinational consultancy, international research organization etc.

\section{Peru}

The Peru case study looked at the design process of RE auctions as a support instrument for RE in the Latin American country. Interestingly, besides increasing national pressure by citizens and NGOs for clean energy sources and a fruitful trip of then vice minister of energy, Pedro Gamio, to Germany from which he returned as a staunch supporter of renewables [49], it was also international pressure which influenced the Peruvian renewables policies. In 2006, Peru and the United States of America negotiated a trade promotion agreement which specifically asked for the adoption of stringent environmental policies [50]. For the Peruvian case study, we conducted 25 semi-structured individual interviews and a group interview with 13 specialists.

\section{Results: Causes and motivations for policy transfer}

Before describing case study results across the eight elements of the analytical framework, it is important to note that concepts like policy transfer are at best an illustration of the real-world process of policymaking beyond borders. In practice, as we will show, policies are not always only 'imported' from the industrialised North to the less-industrialised South. This north-south perspective neglects the fact that often, policies are discussed, designed and implemented to respond to specific 
national characteristics as much as international influences. Furthermore, a North-South perspective somehow assumes reduced agency of local policymakers who are simply 'policy takers' from policy 'makers' in other countries. This rather dichotomic framing of policy transfer does not correspond to the realities on the ground where policies respond to both domestic and international developments and where the flow of communication is not always only from the North to the South but also from the South to South and sometimes even from South to North. This was particularly evident in the Ugandan case, as described in section 4.2.2. However, for the sake of clarity and for the purpose of addressing our research questions in a systematic manner, this paper focuses primarily on examples where policies flowed from the North to the South, highlighting where relevant the broader flows of information in the process of policy transfer.

\section{Causes and motivations}

The first analytical element of our framework addresses the motivation for policy transfer, i.e. the question of why actors engage in policy transfer. According to Dolowitz and Marsh, policy transfer can be a voluntary and a rational process, by which actors learn from another political setting as a rational and intentional decision aimed at addressing a recognized problem or issue. However, policy transfer can also derive from external pressures, like the direct imposition of policies from one jurisdication to another. More often, however, a mix of both, coercive and voluntary elements, can be observed. Accordingly, policy transfer can be understood as a continuum between the two extremes of coercion and voluntariness [23, 24]. Figure 2 provides an overview of what drives policy transfer.
One can see that there are many motivations and triggers for a policy transfer to occur. While some of them are more coercive in nature like 'economic pressure', for example exercised when international financial organisations such as the International Monetary Fund (IMF) demand the implementation of certain policies in exchange for loans, others are more voluntary in nature such as using evidence and experiences from abroad to legitimate domestic decisions taken [23].

Thus, legitimization, functional interdependence between countries, the velocity of technological change, the competition between countries (e.g. for leading the trends of modern policies), as well as the pressure of the political economy between countries, and the trends and challenges in the international agenda, all are important causes of policy transfer $[23,24]$.

Our analysis showed several different causes and motivations in our case study countries- some more voluntary, some more coercive - for policy transfer in the field of renewable energy policy in case study countries (Table 1).

In the case of Peru, both voluntary and coercive elements were present during different stages of the process. In the first stage, voluntary lesson-drawing and prospective evaluation of renewable energy policies were carried out by public and private actors. Stakeholders specifically mentioned the leadership of the ministry of energy and its vice minister, Mr. Pedro Gamio, who visited countries like Germany to learn about renewable energy and who himself was an energy law consultant before becoming a policy maker [49]. In addition, the growing awareness about the country's vulnerability to climate change impacts after the release of the Stern Review in 2006 and the ensuing domestic political debate indicates that policy

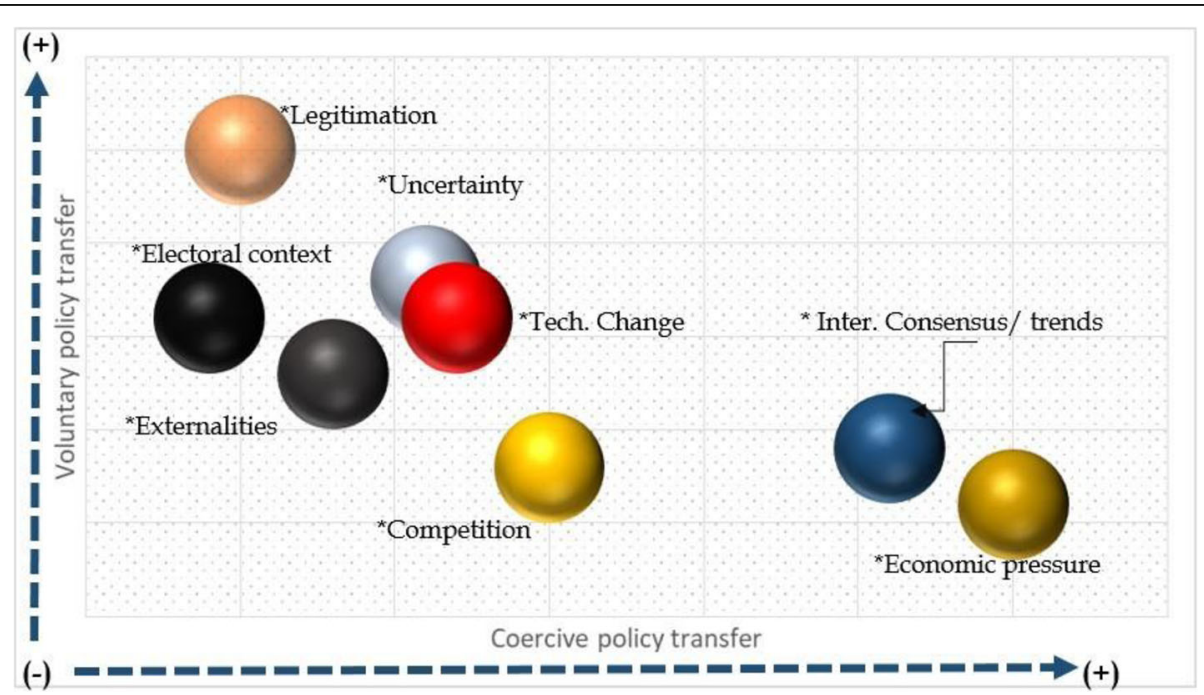

Fig. 2 Causes and motivations as a continuum between pure coercive and pure voluntary policy transfer. Source: Authors elaboration based on Dolowitz and Marsh [23, 24] 
Table 1 Principal causes and motivations for policy transfer concerning RE

\begin{tabular}{|c|c|c|c|c|}
\hline \multicolumn{2}{|l|}{ Countries } & \multirow[t]{2}{*}{ Peru } & \multirow[t]{2}{*}{ Thailand } & \multirow[t]{2}{*}{ Uganda } \\
\hline \multicolumn{2}{|c|}{ Causes/motivations } & & & \\
\hline \multicolumn{5}{|c|}{ Pure Voluntary causes } \\
\hline \multirow[t]{9}{*}{ Mixtures } & Legitimation & $K^{a}$ & K & $\checkmark$ \\
\hline & Electoral Context & & $\checkmark$ & \\
\hline & Uncertainty & $\checkmark$ & K & K \\
\hline & Externalities & & $\checkmark$ & \\
\hline & Technological Change & & & $\checkmark$ \\
\hline & Economic Pressures & K & & \\
\hline & Competition & & & $\checkmark$ \\
\hline & International Consensus/ trends & K & $\checkmark$ & \\
\hline & Others & & & Collaborative \\
\hline Pure coerc & & & & \\
\hline
\end{tabular}

Source: Authors' elaboration based on Dolowitz and Marsh [23, 24]

${ }^{a}$ The letter $\mathrm{K}$ refers to key causal factors observed over the policy transfer process

transfer also involves uncertainties and international trends as causal factors.

However, during the second stage of the policy transfer, coercive factors became more prominent. In 2006, Peru signed a trade agreement with the United States of America (the 'United States-Peru Trade Promotion agreement') which made the upgrade of Peruvian environmental governance part of the trade deal and as a result, a renewable energy support act (Legislative Decree 1002) was implemented. This exogenous pressure, combined with international trends on climate change mitigation policies also led to the creation of the Ministry of Environment in Peru.

In the case of Thailand and Uganda, the cause of the policy transfer seemed to be more voluntary in nature. In Thailand, energy security concerns have been a main driver as well as the objective to legitimise a renewable energy goal. Thailand's successful economic growth during the previous decades had resulted in a rapid and steady increase in energy consumption while domestic reserves were insufficient to meet the rising demand, covered largely by imports of natural gas [51, 52]. The need to shift away from reliance on rapidly dwindling domestic natural gas and lignite resources while also reducing dependence on expensive and potentially insecure energy imports led to structural reforms aimed at reducing imports, enhance energy conservation and boost renewable energy uptake.

In this context, the policy transfer process was primarily to legitimize the policy goal of increasing the share of renewable energy to $8 \%$ by 2011 [53, 54]. RE received a further boost after the change in government in 2001, as well as by the broad support of the government after the coup d'état in 2006, which updated the national energy policy to establish a Feed-in Premium (FiP) (called 'Adder') for Renewables energies (RE) [55-57].
Similar to Thailand, energy security concerns were important for introducing a new RE support policy and for attracting private investments in the renewable energy sector in Uganda. The country suffered major consecutive droughts in the period between 2005 and 2007, which put stress on the hydropower system, the main source of electricity in Uganda. Combined with high oil prices, high diesel generation costs and a shortfall in the electricity supply, this led to an urgent need to diversify energy supply and to exploit the potential of modern technologies. In this way, uncertainty with regards to energy supply coupled with the need to reduce reliance on emergency thermal energy created a fertile ground for FiT policies to be introduced. In addition, some Ugandan policymakers and the national Electricity Regulatory Authority (ERA) sought to legitimize their RE policies by looking to other countries (especially Germany, Spain) in order to draw lessons.

A comparison between the three countries reveals, that motivations for a policy transfer were rather different. Uganda and Thailand were concerned with energy security and uncertainties evolving around energy access, while environmental concerns were high on the agenda in Peru. Also, the implementation of Peruvian renewable support instruments seemed to be more related to international pressure since the US-Peru trade agreement had some significant influence on environmental regulations and the subsequent adoption of renewable support instruments. Relevant actors in all three countries (see below) looked for lessons learnt to other, mainly European countries with Germany being often quoted (and indeed visited) to learn about renewable energy support instruments. This look beyond national borders was often done in order to lend legitimacy to domestic policies, especially in Peru and Thailand. 


\section{Actors involved in the policy transfer process}

When it comes to policy transfer, a wide array of actors can participate in the process. Although policymakers usually take the most prominent roles, other actors such as non-governmental organisations (NGOs) or private sector players do influence the process as well. Often, the roles of the actors, their influence on the policy transfer process and their configuration changes along the way. The Dolowitz and Marsh model identifies nine groups of actors involved in the policy transfer process: elected officials, political parties, bureaucrats and civil servants, pressure groups (which can sway the government's policies from outside government [58]), policy entrepreneurs and experts, transnational corporations, supra-national organizations (with strong influence as information disseminators and advocator of key policy issues at the international level), think tanks and consultants.

When looking at the case studies, our analysis, based on stakeholder engagement, showed that the role of actors in the policy transfer process varies depending on the stage the policy transfer is in - from initial elaborations to final adoption - and on whether the policy transfer is more voluntary or more coercive in nature. Moreover, different actors can intervene in the policy transfer process either by advancing the policy transfer or by hindering it, depending on their stated interest and their power to do so. Often, those cleavages run along the regime-niche dichotomy, as it was the case in Thailand where incumbent actors of the fossil fuel-based regime initially opposed regulation to support RE (Table 2).

\section{Actors in favour of policy transfer concerning renewable energy}

In the first stage of the policy transfer in Peru, political parties, bureaucrats/civil servants, pressure groups and foreign governments were involved in the development of a regulatory framework for the promotion of RE.
Although the support of political parties in the Congress was limited, bureaucrats advocated and elaborated several proposals for a regulatory framework, while some pressure groups such as NGOs, international development partners, networks, and associations as well as universities supported the institutional change towards green energy. To this voluntary action of mainstreaming, lesson-drawing and advocacy on renewable energy, key coercive components intervened in the process in a second stage, namely because of the trade negotiations mentioned above.

In the last stage, predominantly voluntary, the role of actors was centred on the design and the implementation of the support scheme. Thus, three main actor groups were involved: bureaucrats/civil servants, consultants, and foreign governmental bodies. Bureaucrats from the Vice Ministry of Energy pre-defined the type of support scheme that was going to be further developed and adopted in Peru and decided on renewable energy auctions. The final design of the support scheme came mainly from government officials in the Ministry of Energy and Mines (MEM), the Regulatory agency for the energy and mining sector-Organismo supervisor de la inversion en Energía y Minería (OSINERGMIN), consultants, state agencies, power companies and foreign organisations such as the Gesellschaft für Internationale Zusammenarbeit (GIZ) from Germany, a large coalition of actors when it comes to policy transfer in Peru.

In the case of Thailand, the type and role of the actors were also related to the stage of the policy transfer as well as to the fact that the transfer process was largely a voluntary one, based on lesson-drawing, particularly from RE support programmes in Germany and the UK. In the first stage of the development and evolution of Thailand's FiT policy for RE (the Adder programme), many actors participate in the process of developing the Adder scheme. Elected officials, such as the former

Table 2 Actors involved in the policy transfer process concerning renewable energy

\begin{tabular}{llll}
\hline Countries Actors & Peru & Thailand & Uganda \\
\hline Elected officials & & $K^{*}$ & $\checkmark$ \\
Political parties & $\checkmark$ & $\checkmark$ & $\mathrm{K}$ \\
Bureaucrats/civil servants & $\mathrm{K}$ & $\checkmark$ & $\checkmark$ \\
Pressure groups & $\checkmark$ & $\mathrm{K}$ \\
Policy entrepreneurs/experts & $\checkmark$ & & $\checkmark$ \\
Transnational corporations & $\checkmark$ & $\checkmark$ \\
Supra-national organizations & & $\checkmark$ & $\checkmark$ \\
Think tanks & & & \\
Consultants & $\checkmark$ & K- [Foreign Governments (US)] &
\end{tabular}

Source: Authors' elaboration based on Dolowitz and Marsh [23, 24]

*The letter $\mathrm{K}$ references to key actors in the policy transfer process 
Ministers of Energy contribute decisively to legitimizing the Adder program and civil servants of governmental agencies such as the Department Alternative Energy Development and Efficiency (DEDE) and the Energy policy and planning office (EPPO) were very active in the process of designing renewable energy policies. It is important to note, that delegations from the ministry of energy as well as from EPPO took part in a tour throughout Europe in order to learn from those countries' experiences with RE support instruments.

Pressure groups including power utilities and private small power producers interested in grid-interconnection of small-scale RE also had a relevant role in the policy transfer process. The private power producers, though not involved in the earlier phases of policy transfer, exerted a certain influence in the later phases of public consultation to modify Thai FiT policy as well as for its substitution with RE auctions between 2013 and 2017. Likewise, policy entrepreneurs and experts from policy research institutions, universities and local NGOs were involved a great deal in the learning processes and recommending the suitable RE instruments as well as giving suggestions to adapt the FiT policy according to the Thai context. Finally, think tanks played a relevant role in policy lesson-learning in the early phase of transfer, and in regulations drafting for the Ministry of Energy while international agencies participated in the policy transfer process, mainly acting as policy consultants.

As for the case of Uganda, the principal actors involved in designing RE support policies - which one could group into three distinct phases - were the ERA, policymakers from the Ministry of Energy and Mineral Development (MEMD), as well as external consultants especially during the Phase II of the FiT program and Phase III (GETFiT) according to interviews stakeholders. In the first phase of the FiT, which was exploratory in nature (Uganda being among the first African countries to introduce FiTs), ERA and MEMD were driving the process of policy adoption and diffusion. The instrument was inspired by the German FiT model which was chosen as a model over a USstyle instrument of renewable energy standards. Moreover, German institutions such as the GIZ/KfW were in talks with Ugandan policy makers about the potential design of the policy instrument. Other actors, while not directly involved, created an environment conducive to RE support policies through their advocacy for liberalization and power sector reforms. The FiT in the first phase built on this core principle: promoting decentralized and smallscale power generation by independent players. In this phase, ERA and MEMD focused on legitimizing the FiT program. In determining the FiT rates, the elected officials and political pressure groups played an influential role. In Phase II of the Uganda Renewable Energy Feed-In Tariff (REFiT), external consultants such as CAMCO were involved to review the FiT and provide expert judgment. This also served the purpose of convincing those stakeholders which resisted (elected officials) and of legitimizing the policy instrument. Quite interestingly, CAMCO also brought with them some expertise from their experiences with FiTs in countries such as South Africa. Therefore, one could argue that the policy transfer process in Uganda was not only between the global North and the global South, but also between to Southern countries.

Phase III combined a FiT premium scheme with RE auctions and external consultants, independent advisors and organizations such as The United Nations Environment Programme (UNEP), the Frankfurt School of Finance and Management and the German GIZ played an influential role in shaping and implementing the policy instrument. Together with local consultancies such as CAMCO, they were involved in drawing on key lessons and experiences (both positive and negative) from Germany and South Africa (in particular), adapting and matching the different ideas to suit the local economic and political context, and also providing support in building capacities of the local institution to be able to successfully implement the policy/program.

\section{Actors against and resistance to policy transfer concerning RE}

However, actors can not only play a supporting role for policy transfer processes to take place, but can also hinder the process. Often, those actors assuming a more hindering role are found in the fossil fuel-based regime, which often opposes or at least doesn't support an increased renewable energy uptake. In the case of Peru, the main pressure group against RE penetration policy was the National Society of Mining, Oil, and Energy- Sociedad Nacional de Petróleo Minas y Energía (SNMPE), an industry association representing oil, natural gas, and hydroelectric industry. Organized in the SNMPE, the incumbents of the energy sector resisted the promotion of $\mathrm{RE}$ which was seen as a measure which would also introduce more competition to the energy market. Other civil servants opposed or were resistant to the implementation of the regulations, such as bureaucrats from the MEM who considered hydro and thermal electricity production as the priority in Peru. Finally, although not in open opposition, Congress generally showed limited support for the various proposals to enact the regulatory framework for RE $[49,59]$.

In the case of Thailand, utilities, particularly the Electricity Generating Authority of Thailand (EGAT), were the principal players opposing RE policies according to the stakeholders engaged. Interestingly, the structure of Thailand's power market with a single vertically integrated utility, the state-owned EGAT, owning and managing the large majority of power generation assets and the entirety of the transmission network gives EGAT some significant leverage to 
oppose legislation for a more decentralised and diverse market. Not surprisingly, EGAT imposed a strong resistance to the policy transfer of RE support instruments.

As for the case of Uganda, the opposition or resistance was not expressed outright by any consolidated interest group. Instead, it was expressed primarily by selected independent elected officials who expressed concern about the tariff rates and the way those rates were calculated. Furthermore, there was resistance from one of the independent power producers, who was expecting a higher tariff rate. In the end, however, Uganda reached a compromise as a result of stakeholder negotiations between ERA and the power producer.

When comparing the actor coalition in the three countries, it is clear that policy transfer is often a multistakeholder endeavour. Different types of actors have influenced the policy transfer and implementation process in all three countries, although the process is often driven by elected officials and national bureaucrats. International organisations have been playing a more prominent role in Peru where trade negotiations coincided with deliberations on renewable support instruments but both Thailand and Uganda also made use of connections with international entities such as the GIZ. Quite interestingly, the Ugandan policy transfer process incorporated insights from other sub-Saharan African countries, namely South Africa, thus conforming that policy transfer is often not a clear-cut North-South process where policies flow from the North to the South, but that lessons and best practice examples can also flow from Southern countries to other Southern countries.

Nevertheless, Europe can still serve as an example. For instance, regime actors such as utilities and fossil fuel lobby organisations worked against implementing and transferring renewable energy support policies, particularly in Thailand and Peru, a situation not unlike the one experienced in Germany (see [60]). Ugandan regime actors seemed to have assumed a less confrontational role.

\section{Object of the policy transfer}

When it comes to what exactly is transferred in policy transfer, there is a variation from an entire policy program is transferred, while in other cases, only a policy idea may be transferred. Moreover, even if a policy programme is transferred, the details and nature of the instruments and institutional set-ups which translate these programmes into action might differ in the borrowing country from the instruments in the lender country $[24,61]$.

According to Dolowitz and Marsh, we consider eight categories for analysing the objects of transfer: policy goals, policy content, policy instruments, policy programmes (which, according to Dolowitz and Marsh are specific actions to deliver on policies), institutions, ideologies, ideas and attitudes and negative lessons (Table 3).

In Peru, we observed that several objects had been transferred, namely the policy content, policy instruments as well as negative lessons learnt from renewable energy support in Spain and Germany. The knowledge for designing policies as well as the specific instruments to achieve the local renewables target was a central element of the policy transfer. For example, the Legislative Decree 1002 contains some elements from the German "Renewable Energy Sources Act", the EU country's wellknown flagship renewable support instrument. Similarly, Decree 1002 contains elements from the Spanish Royal Decree 436/2004 [49]. Experiences from Spain and Germany also provided important lessons on why RE auctions would be the most appropriate support scheme in the Peruvian context, with particularly the regulatory agency OSINERGMIN gathering lessons learnt from Spanish and German partners in the implementation of their particular FiT schemes [62].

In the case of Thailand, the implementation process of the Feed in premium (FiP) program Adder indicates that the chief objects of policy transfer were ideas and attitudes, negative lessons learnt and policy instruments themselves. The process began with a review of renewable support instruments that were effective in a variety

Table 3 Objects of the policy transfer

\begin{tabular}{lcc}
\hline Country & Peru & Thailand \\
Object of the P.T. & $\checkmark$ & $\checkmark$ \\
\hline Policy goals & $\checkmark$ & $\checkmark$ \\
Policy content & $\checkmark$ & $\checkmark$ \\
Policy instruments (tools for achieving goals) & & $\checkmark$ \\
Policy programs (specific means of the course of action) & \\
Institutions & & $\checkmark$ \\
Ideologies & & $\checkmark$ \\
Ideas and attitudes & $\checkmark$ & $\checkmark$ \\
Negative lessons (what does not work) & & $\checkmark$ \\
\hline
\end{tabular}

Source: Authors' elaboration based on Dolowitz and Marsh [23, 24] 
of countries, followed by the selection of those measures that were feasible in Thailand's context, and in the end, several focused studies on selected instruments.

In addition, the policy transfer process also processed lessons learned from the Renewable Portfolio Standard (RPS) scheme in the UK and from several states in the US, as well as lessons concerning China's decision to shift from RPS to a FiT program. Finally, the policy instruments of FiT/FiP drew on key elements of the German FiT scheme, in particular, the price mechanism, in order to legitimize the Thai renewable energy policy.

In the case of Uganda, the object of the policy transfer has been centred mainly on the policy goals, the policy content and the policy instruments. Lessons from countries such as Germany were applied in the design of the instrument and helped to shape the specific context of the FiT. Besides some lessons from Germany, the Ugandan case also revealed that experiences from the US RPS scheme were incorporated into the Ugandan FiT policy. Moreover, Ugandan regulators gathered information, ideas, and knowledge not only from instruments applied in the industrialised North but also from a number of developing country contexts (including Brazil, South Africa and Sri Lanka) thus adding to the observation that sometimes, policy transfer is a process also happening from South to South.

As was the case in Thailand, the FiT in Uganda also drew on the key elements of the German FiT scheme, in order to legitimize the RE policy. Furthermore, the Phase III i.e. the GET-FiT program drew heavily on the policy program developed by the Deutsche Bank Asset Management Team in order to offer an innovative strategy for developing countries to attract capital in their RE sector. This program was modified and adapted to make it relevant to suit the local context. It was more than just a policy instrument; it encompassed a package of instruments, offering direct incentives, risk mitigation strategies, standard agreements and capacity strengthening of local institutions. Hence, while in the initial phases, the object of policy transfer remained limited to policy goals and policy instruments, the latter phase III broadened the instruments itself by adding elements such as risk mitigation strategies which go beyond traditional RE policies such as FiTs.

Comparing what actually is transferred in the policy transfer process across case study countries reveals that not only is policy transfer not always a journey from North to South but also that policies are rarely implemented without adaptation to local contexts. Indeed, all three countries, while seeking inspiration from abroad, spend some significant time to make the different policies and programmes "work" in local contexts. During this process, negative lessons learnt in other countries proved to be an important factor in all three case study countries and elements of renewable support policies and strategies from abroad (Europe, but also SubSaharan Africa and Asia) found their ways into national policies and programmes, particularly in Peru.

\section{Spatial scale of the policy transfer}

With regards to the spatial aspect of the policy transfer, policymakers can look to three levels of governance: the international, the national and the local level. Not only can sub-national units of government draw lessons from each other but also the national government can draw lessons from lower levels of government, which in turn can draw upon the national government. Finally, the lesson can be drawn from the international level be it voluntarily or more in a coercive manner due to, for instance, economic pressure, as described above (Dolowitz and Marsh [23, 24] (Table 4).

Our analysis shows that actors in all three case study countries looked to other countries for positive as well as negative experiences in RE development. Generally, those 'borrowing' countries were also those with a longer experience of FiTs although some inspiration was also sought in countries like Brazil or Sri Lanka.

In the case of Peru, the policy transfer happened not only from abroad but knowledge was also acquired from local experiences. But as described above, Germany and Spain where the main jurisdictions, Peruvian policy makers drew lessons from, particularly when choosing renewable auctions as support instruments over fixed feed-in tariffs. Thus, the regulatory framework follows elements from German and Spanish legislation as a "hybrid" with adaptations to the Peruvian context [49].

In Thailand, Germany was also an important country when it comes to the transfer of knowledge and policies. However, the German experience was not the only jurisdiction Thai stakeholders looked to for lessons when designing their policies. The UK, the USA and China also

Table 4 Spatial scale of the lesson drawing

\begin{tabular}{llccccc}
\hline From & Germany & Spain & EU & South & UK & US \\
To & & $\checkmark$ & & \\
\hline Peru (local experience) & $\checkmark$ & $\checkmark$ & $\checkmark$ & $\checkmark$ \\
Thailand (local experience) & $\checkmark$ & & & $\checkmark$ \\
Uganda & $\checkmark$ & $\checkmark$ & $\checkmark$ & $\checkmark$ \\
\hline
\end{tabular}

Source: Authors' elaboration based on Dolowitz and Marsh [23, 24] 
provided for some inspiration. For example, the Chinese experience influenced the decision to switch to FiTs and the establishment of an independent regulatory agency in 2008 is said to have been modelled after the UK's office of Gas and Electricity Markets (OFGEM) [46, 63, 64].

In the case of Uganda, the spatial scale heavily involved drawing positive and negative lessons from the experiences of Germany and Spain with regards to FiT and renewable auctions, and also lessons from the US with regard to Renewable Portfolio Standards (RPS). These lessons served as important sources of knowledge for choosing and designing the Ugandan FiT instrument. Also, successful experiences in South Africa with RE auctions influenced the implementation of phase III of Ugandan renewables support, Uganda being only the second country (after South Africa) which experimented with auctions.

When looking at all three case study countries, it is clear that Europe, particularly Germany, has provided inspiration for local policy makers on how to design renewable energy support policies. Other jurisdictions such as the US, the UK or Spain also provided for some significant knowledge transfer. But besides this North-South transfer, the Ugandan case study shows that knowledge, ideas and lessons can also flow between countries of the global South while experiences in Thailand show that policy transfer might also happen often between countries which are geographically close to each other.

\section{Mechanisms of policy transfer}

One important part of the analysis is to address the question of how policy transfer is carried out, or how the mechanisms of policy transfer work [23, 24, 65]. Dolowitz and Marsh propose several mechanisms of policy transfer: copying (which implies very little or no changes to the policy), hybridization and synthesis, emulation (which implies some adaptations to local contexts) and inspiration where little (or nothing) is actually drawn from other jurisdictions (Table 5).

In the case of Peru, policy transfer was mainly carried out using inspiration and emulation as mechanisms. For example, inspiration was the mechanism of policy transfer during the period 2006-2008 when leading bureaucrats from the MEM were inspired by solar and wind projects in Germany, which motivated them to launch similar processes to increase renewables penetration in Peru.

Emulation was then used to design the regulatory framework and the design of the specific support scheme in the form of auctions based on experiences in Germany and Spain. Indeed, by choosing auctions over Feed-in tariffs, Peruvian stakeholders chose to adapt experiences from abroad to local contexts.

In Thailand, the degree of transfer went from copying to hybridization, especially as for the design and implementation of the FiP scheme, Adder. During the early phase (2002-2007), policymakers were keen on copying the German FiT policy that had proven successful for $\mathrm{RE}$, but local political, institutional and market contexts such as the quasi monopoly of EGAT forced the policy transfer to involve some degree of adoption and adjustments. For instance, the regulatory and administrative design of renewable energy support drew on the experience of the Thai Very Small Power Producer (VSPP) net-metering program and the policy transfer was finally implemented in a form that combined traits of German FiT policy with traits from Thailand's previous Small Power Producers (SPP) bidding scheme and net-metering regulations.

In Uganda, the transfer evolved from inspiration and emulation to hybridization. Similar to the experience in Thailand, regulators were inspired by the German FiT scheme in phase I, which played a key role in inspiring renewable support in Uganda. However, German RE policy instruments where not simply copied, but were modified to the Ugandan context and the support instruments which were finally adopted did also include lessons learnt from other countries in the region such as South Africa and Rwanda. Nevertheless, German actors such as the KfW supported Ugandan government in setting up a programme which went beyond simple FiTs. As part of the new GETFiT programme, the World Bank could be called upon to issue partial risk guarantees to $\mathrm{RE}$ project thus lowering the risk profile, an instrument which goes beyond simple FiTs.

A comparative view of the three case study countries reveals that while initially the policy transfer might start out as a copying mechanism, experiences in Uganda, Thailand

Table 5 Evolution of policy transfer mechanisms

\begin{tabular}{llll}
\hline & Policy transfer process & & \\
\hline Peru & $2006 \rightarrow 2007$ & $2007 \rightarrow 2008$ & $2008 \rightarrow 2009$ \\
& Inspiration & Inspiration & $2013 \rightarrow 2017$ \\
Thailand & $2002 \rightarrow 2007$ & $2009 \rightarrow 2013$ & Hybridization \\
& Copying and emulation & Emulation & $2012 \rightarrow 2014$ \\
Uganda & $2005 \rightarrow 2007$ & $2007 \rightarrow 2010$ & Emulation and Hybridization \\
& Inspiration & Inspiration and Emulation
\end{tabular}

Source: Authors' elaboration based on Dolowitz and Marsh [23, 24] 
and Peru show that policies and support instruments are not transferred without modifications. Indeed, in every country, stakeholders soon adapted lessons learnt from other countries to local contexts in order to implement suitable RE support instruments, policies and programmes.

\section{Constraints on policy transfer}

When looking at policy transfer as a practice, it is also useful to investigate its constraints. Dolowitz and Marsh propose the following set of constraints or barriers: the level of complexity (assuming that the more complex the policy is, the more difficult the transfer will be), past policies (if innovation is hindered by those past policies), structural and institutional feasibility and a set of features which they call 'ideology, cultural, proximity, technology, economic, bureaucratic and language'.

In our analysis we chose to supplement this constraint category with potential drivers of policy transfer, i.e. looking at what kind of factors might support the process (Table 6).

In the Peruvian case, there were two main barriers related to the policy transfer process. The first constraint was a mix of technology and ideological constraints since some pressure groups had been vocal in their opposition to RE support policies, citing economic reasons (RE was perceived as being too expensive) as well as technological reasons (RE was perceived as European model which was thought not to work in Peru because of lack of technical experience). The second main barrier was the availability of large reserves of natural gas and the high potential of hydroelectricity production, with both sources appearing more competitive and less burdensome on the taxpayer compared to renewable energy and needed support schemes.

However, there were also multiple drivers of the policy transfer process and many of them coincide with the different aspects of the causes and motivations observed above. For example, the external pressure to adopt the Legislative Decree 1002 in order to comply with the requirements of the US-Peru Trade Agreement can be considered an important driver for Peruvian environmental policies and subsequently for policy adoption. Furthermore, and despite the pressure from certain lobby groups, environmental awareness and lobby work by other stakeholders played a supporting role in the policy transfer process.

The Thai case study revealed a somewhat complex picture, describing both barriers and drivers. Thai RE support policies clearly benefited from an active interest of policymakers and policy entrepreneurs within ministries who actively worked on renewable support policies, making use of political and bureaucratic resources. Ideological features played a role as well since energy security was seen as a co-benefit of increasing the share of renewable energy. On the other hand, stakeholder engagement in Thailand also revealed some barriers to renewable support policies.

One major shortcoming was the structure of the electricity market which - in its centralized form and dominated by the state-owned incumbent utility EGAT - was seen as counter-productive to increased renewables uptake. Indeed, in this case, structural feasibility posed a constrain on the policy transfer process and limited regulatory resources were identified as a barrier. Those limited resources were also cited for the development of a lucrative secondary market for RE permits after the Adder programme was adopted, where permits would be traded amongst stakeholders, without capacity actually being build. In the same vein, the authority of the regulatory body was assessed as having insufficient powers to regulate RE uptake. Here, past policies and structural constraints clearly had a negative impact on the policy transfer process.

In the case of Uganda, structural feasibility proved to be a driver and not a barrier to the policy transfer process. According to interviewed stakeholders, a coherent, rather independently elaborated support framework for RE under the leadership of ERA but facilitated by international consultancies and institutions drove the policy transfer process forward. Nevertheless, along the way, a certain number of tensions arose between the independent regulator ERA and different ministries for instance about the tariff rates. Also, the failure to attract private investment in renewables in Uganda might have put a break on RE development in the first phase of the support policies, but lessons learnt were later used to build a large coalition with national and international institutions in phase III to boost RE uptake.

Table 6 Main drivers and barriers

\begin{tabular}{llll}
\hline & Peru & Thailand & Uganda \\
\hline Complexity of the policy & $\mathrm{B}^{*}$ & & $\mathrm{~B}^{*}$ \\
Constraints set by past policies & $\mathrm{B} / \mathrm{D}^{*}$ & $\mathrm{~B}^{*}$ & $\mathrm{D}^{*}$ \\
Structural and institutional features & $\mathrm{B}^{*}$ & $\mathrm{D} / \mathrm{B}^{*}$ & $\mathrm{~B}^{*} \mathrm{D}^{*}$ \\
Political, bureaucratic and economic resources & $\mathrm{D}^{*} \mathrm{~B}^{*}$ & $\mathrm{~B}^{*}$ & \\
Ideological and cultural features & & $\mathrm{D}^{*}$ & \\
\hline
\end{tabular}

Source: Author's elaboration based on Dolowitz and Marsh [23, 24]

* Drivers (D)/Barriers (B) 
Comparing case study countries suggests that barriers which might arise during the process have the potential to stymie policy transfer. For instance, the complexity of policies in the lender countries often make it difficult for the borrower countries to adopt the same policies without significantly amending them and adapting them to local contexts. This make contextual factors such as how institutions are functioning and cooperating with each other a key factor of successful policy transfer. Also, policy decision taken in the past, as seen in Thailand, often hinder policy transfer since for instance market structures in the lender countries are more conducive to RE support than in borrower countries. Contextual factors such as the state of the economy were found in all case studies, while the Peruvian case was the most explicit in acknowledging how international pressure can influence the policy transfer process.

\section{Policy success and policy failure}

Whether policies and their transfer can be deemed "successful" and against which criteria such a success is to be measured is still debated in the literature. Nevertheless, Dolowitz and Marsh propose three factors which might have a negative impact on the policy transfer [23, 24]. First, the borrowing country might have insufficient information about the policy, its institutions and how it operates in the lending country, thus leading to uninformed transfer. They further suggest the category of incomplete transfer when essential elements of the borrowed policy are not transposed. Lastly, inappropriate transfer, would occur when contextual factors such as political, economic or even ideological ones are overlooked [24].

As for the Peruvian case the process could be assessed as a successful policy transfer since the process was neither uninformed, incomplete or inappropriate. Knowledge from abroad has been applied to the policy framework (e.g. Legislative Decree: DL 1002) and negative lessons and recommendations obtained from the interaction with actors in Germany and Spain for the design of the policy instrument informed the policy's implementation.

The fact that in Thailand, the FiT was transferred from abroad and that it has been adopted in Thai contexts indicates, in general, a successful process. The short-term RE targets set in the energy policy 2008 were not fully achieved by 2011 [57] and the difficult institutional structure as well as the significant revision of FiT mechanisms, indicate some level of incomplete and inappropriate transfer. Nevertheless, the policy's implementation helped to establish Thailand as a pioneer in renewables promotion in the region.

In the case of Uganda, the analysis points to a general success of the policy transfer, across the three phases with some shortcomings in phase I, notably with attracting private investment in RE capacity. Private investment gained traction in the later phases, when FiT premiums and auctions where implemented as well as in phase III, when the GETFiT programme came to fruition. Under the Phase III GET FiT program, 17 projects were implemented with a total installed capacity of nearly 160 MW [66].

Overall, all three countries have implemented RE support policies. This process was not necessarily a straight-forward one and bumps in the road necessitated amending and adapting the policies, particularly in Thailand and Uganda. However, the method used to analyse these case studies does not seek to assess whether policy transfer was indeed successful in boosting the share of renewable energies or whether it was successful from a socio-economic point of view. Rather, they focus on the process of policy transfer itself, concluding that policies seem to have successfully transferred from one jurisdiction to another. Moreover, it might be argued that what constitutes a "success" when it comes to a policy transfer, is still open for debate.

\section{The transfer process and the policy making cycle}

This last category is an addition to the Dolowitz and Marsh framework (although actors discuss it as an area of further research) and is based on public policy theory and the commonly used policy cycle. In a nutshell, policy making can be understood as a cycle, starting from agenda-setting and policy formulation, leading to decision making and implementation to finally evaluation of the policy [44]. Assessing when in the policy making process local policies are inspired by foreign policies and when lessons and knowledge is transferred thus gives a more complete understanding of how policies, lessons and knowledge flows from one jurisdiction to another (Table 7).

In the case of Peru, elements from abroad influenced particularly the early stages of the policy making cycle. For instance, increasing environmental awareness in the wake of the Stern report led policy makers to look to other countries to find solutions to increase the share of renewable energies.

Similarly, in Thailand, the clearest form of policy transfer was at the beginning of the policy cycle. Several stakeholders consulted argued that Thai governmental delegations were in contact with ministerial colleagues

Table 7 Policy-making stage of the transfer process

\begin{tabular}{llll}
\hline & Peru & Thailand & Uganda \\
\hline Problem definition and agenda setting & $\checkmark$ & $\checkmark$ & $\checkmark$ \\
Policy formulation & $\checkmark$ & $\checkmark$ & $\checkmark$ \\
Decision making and policy implementation & $\checkmark$ & $\checkmark$ & $\checkmark$ \\
Policy evaluation & & $\checkmark$ & $\checkmark$
\end{tabular}

Source: Author's elaboration based on Dolowitz and Marsh [23, 24] and Jann and Wegrich [58] 
in the EU (such as German officials) as well as with institutions such as the GIZ to learn from the German FiT experience. Nevertheless, once implemented, changes to the Adder program (and the replacement of the scheme with FiTs) have entailed some bilateral form of communication as well, not only on the political level but also between EPPO and German utilities. Therefore, while policy transfer might have been the strongest in the initial phase, the transfer might have happened throughout the policy-making cycle while at the same time, Thai policymakers clearly took into consideration national and local specificities.

In Uganda, policy transfer was also the most prominent in the beginning of the policy making cycle. However, elements of policy transfer were observed in the later stages, particularly during the evaluation of phase I where policy makers then reached out to international organisations and independent consultants to adapt international RE support policies to local needs.

It is interesting to note that in all three countries, the beginning of the policy making cycle (problem definition, agenda setting and policy formulation) were the most susceptible to the transfer of policies, lessons and knowledge from one jurisdiction to the other. However, the difficulty of quantifying those transfers and the insufficient sample size are not sufficient to make this a general conclusion.

\section{Discussion and conclusions}

Low-carbon technologies, including especially renewable energy technologies, need to be much more widely deployed in order to meet climate and energy policy goals. But technological innovation, while necessary, is only one aspect of this endeavour. The right policy environment has to be in place as well, to support technological innovation and increase the uptake of low-carbon technologies. Some countries joined the efforts on climate change and renewables earlier than others and have therefore acquired significant experience as to what works in terms of a facilitative policy environment. In the same vein, their experiences can also provide valuable lessons as to what did not function and what negative impacts (on society, on the economy etc.) were felt due to specific policies. It is therefore logical that countries with less experiences in one issue area look to those first mover countries for lessons learnt and knowledge gained. When it comes to policies, this dynamic of lesson learning is often referred to as policy transfer.

Our paper contributes to deepen the understanding of the policy transfer process by shedding light on many details of this process by comparing experiences in three case study countries on three continents. Further research will be needed to confirm or nuance our insights and the sample of three countries while illustrative is not sufficient to draw general conclusions about cases of policy transfer in all contexts. Nevertheless, several observations can be made.

Our empirical findings show that policy transfer concerning support instruments for renewable energy technologies has occurred in the three countries analysed and that the processes have followed different paths of learning and implementation.

With regards to the causes and motivations behind policy transfer, we observed that efforts to legitimize certain national policy decisions as well as the feared impacts of climate change proved to be key motivations to look for other countries' experiences with tackling these issues. Also, uncertainty with regards to issues such as energy security (in the case of Thailand) and/or future climate patterns (in the case of Uganda) proved to be a prime motivation for the policy transfer process. As the case of Peru has shown, developments in the international governance landscape such as trade negotiations can also have an impact, thus pointing to the fact that in some contexts, coercion might also play a role in the policy transfer process.

When it comes to the different actors involved in the processes of a policy transfer, the empirical findings show that both actors from inside the government and actors from outside can play an important role. Likewise, the type and role of the actors were not the same in each stage of the policy transfer, pointing to the fact that different stages - from problem definition to policy adoption- might encourage a different set of actors to become active. For example, while governmental stakeholders and bureaucrats in the administrations of studies countries often initiate the policy transfer, lobby groups or external experts and consultancies often join the process later on (Uganda, Thailand, Peru). Sometimes, those external stakeholders are specifically invited in later stages to adapt policies from one jurisdiction to the specific circumstances on the ground (Uganda). It therefore seems that policy transfer usually involves a rather large panoply of actors which can both hinder or drive the policy transfer process forward and whose configuration changes along the process of the transfer. Moreover, in all three case study countries we observed that stakeholders from lender countries were involved in the process.

Concerning the object of transfer, policy goals, policy content, policy instruments and lessons learnt based on the negative experiences in the lender countries, are all present in the policy transfer processes of the three borrower countries analysed. It is important to note, that lessons and best practice examples did not only come from OECD countries like Germany, Spain, the UK, or the US, but also from China (in the case of Thailand) and South Africa in the case of Uganda, thus pointing to a South-South conduit for policy transfer in addition to the more commonly studied north-south transfer. Nevertheless, Germany and its flagship energy transition 
laws were mentioned quite often by local stakeholders as a source of inspiration in all three case studies.

When it comes to the mechanism of policy transfer, it is noteworthy that no transfer process was carried out by purely copying other countries RE support instruments. In Uganda and Peru, we observed an inspirational phase at the beginning of the policy transfer process while Thailand came closest to emulating German FiTs. However, local circumstances soon made it necessary to adapt foreign policies to local contexts. This was the case in Thailand, where the support instrument had to be adapted to the highly centralised and monopolised electricity market and in Uganda, where RE support policies went beyond simple economic instruments and also included adapting the institutional set up. In the case of Peru, the policy transfer process included two stages of inspiration, and a final stage of emulation, related to the policy regulatory framework and design of the support scheme respectively. In the same vein, elements of policy transfer can be found in all stages of the local policy making cycle. However, it seems that while information flowed from lender to borrower countries throughout the process, that the stages most susceptible to incorporate lessons and knowledge from abroad where the stages of agenda-setting and policy formulation, although quantifying this dynamic is difficult and these observations remain anecdotal.

Another observation to be made is that contextual factors in borrower countries (adopter countries) play a prominent role in the policy transfer process and can both constitute a barrier and a driver for those processes. For instance, renewable support in Peru was also hindered by the presence of large gas reserves (deemed to be cheaper) while the structure of the electricity market was deemed not very beneficial for RE deployment in Thailand, thus illustrating the importance of past policies and institutional features impacting policy transfer. Economic issues such as increasing costs of renewable subsidies have been observed in Uganda, an experience not unlike the one in Germany where generous feed-in tariffs were not adapted to falling technology costs, thus driving up overall costs for society of the instrument.

When it comes to the question of whether the policy transfer in the target countries was a success, our observations, although qualitative in nature, point to a careful positive assessment. Although bumps have been observed along the way and policies had to be adapted to local context in a quite substantial manner, there was little evidence for uninformed, incomplete or inappropriate policy transfer. According to the Renewable Energy Policy Network, all countries still have dedicated RE support policies in place as of 2018 [25].

Our study shows that the conceptual model of policy transfer offers a number of different analytical tools that facilitate an evaluation of the design and implementation of different policies and institutions in one country or region can be applied in other countries or regions. This conceptual model and the comparative analysis of the three cases found that technology and policy transfer are more appropriately seen as continuous and evolving processes of change rather than one-off events. Furthermore, policy transfer is significantly influenced by contextual factors such as the institutional set up in the borrower country or economic factors. And while inspiration and knowledge are often sought in first mover countries in the OECD, who had some significant experience in RE support, transferred policies had to be adapted to local contexts, often in dialogue with a diverse set of stakeholders.

Finally, it is worth mentioning that the speed of communication and the increasing integration of information systems around the world is likely to affect policy learning and policy transfer into the future. At the same time, there must be a willingness across different countries or regions for international cooperation in order for policies to be successfully transferred or for significant learning to occur.

\section{Abbreviations \\ DEDE: Department of Alternative Energy Development and Efficiency; DL: Legislative Decree; EGAT: Electricity Generating Authority of Thailand; EPPO: Energy Policy and Planning Office; ERA: Electricity Regulatory Authority; ERC: Energy Regulatory Commission; EU: European Union; FiP: Feed-in Premium; FiT: Feed-in-tariffs; GET FiT: Global Energy Transfer Feed-in Tariff; GIZ: Gesellschaft für Internationale Zusammenarbeit; IMF: International Monetary Fund; IS: Innovation Systems; KFW: Kreditanstalt für Wiederaufbau; MEM: Ministry of Energy and Mines; MEMD: Ministry of Energy and Mineral Development; MLP: Multi-level perspective; NDCs: National Determined Contributions; NGO: Non-Governmental Organizations; R\&D: Research and development; RE: Renewable Energy; REFiT: Renewable Energy Feed-In Tariff; RES: Renewables Energies; RPS: Renewable Portfolio Standard; SDGs: Sustainable Development Goals; SPP: Small Power Producers; TiS: Technological Innovation Systems; UNEP: The United Nations Environment Programme; US: United States of America; USAID: United States Agency for International Development; VSPP: Very Small Power Producer}

\section{Acknowledgments}

The authors wish to thank all interview respondents and reviewers for their time and their valuable contributions. Harro van Asselt developed the initial concept for the analysis of policy diffusion and provided background material on energy and climate policies. Anne Nyambane (SEI) provided useful background material for the article. Clarisse Kehler Siebert (SEI) conducted a review and provided editing and reference support for an earlier version of the paper. Oliver Johnson (SEI) provided useful inputs and Aurélie Faure-Schuyer (CEPS) reviewed an earlier version of the paper.

\section{Authors' contributions}

SB substantially re-worked and re-analysed many sections of the paper and added additional insights from the literature to create the final version of the paper, based on initial case study information and an earlier draft. TS established the initial comparative framework for the study, supervised the Master's students who participated in the research, and provided initial material for the paper. $A B$ further elaborated the conceptual framework for the comparative analysis and carried out the Peru case study. FXJ integrated the various components of the study and organised the structure of the paper and the comparisons. JERM developed a more systematic approach to the conceptual framework and comparisons and edited the case study materials further. $\mathrm{MH}$ conducted a case study in Thailand. PLB conducted the case study in Uganda. JH supported the case study in Uganda and provided material on technology transfer. All authors read and approved the final manuscript. 


\section{Funding}

This project has received funding from the European Union's Horizon 2020 research and innovation programme under grant agreement No. 642242.

\section{Availability of data and materials}

There are no statistical datasets but results from interviews and related materials are available on reasonable request.

\section{Ethics approval and consent to participate}

The research was based on interviews and observations. Interviewees were aware of and approved the writing of this paper. All conclusions remain the sole responsibility of the authors.

\section{Consent for publication}

Not applicable.

\section{Competing interests}

The authors declare that they have no competing interests.

\section{Author details}

'Stockholm Environment Institute, Stockholm, Sweden. ${ }^{2}$ Amphos 21 Consulting, Barcelona, Spain. ${ }^{3}$ Stockholm University, Stockholm, Sweden. ${ }^{4}$ KTH Royal Institute of Technology, Stockholm, Sweden. ${ }^{5}$ Technical University of Denmark, Lyngby, Denmark.

\section{Received: 12 November 2018 Accepted: 28 November 2019 Published online: 13 February 2020}

\section{References}

1. Bodansky D. The Paris climate change agreement: a new hope? Am J Int Law. 2016;110(2):288-319.

2. IISD (2018). Earth Negotiations Bulletin- A Reporting Service for Environment and Development Negotiations 12 747. International Institute for Sustainable Development-IISD. Retrieved from http://enb.iisd.org/.

3. Nerini FF, Tomei J, To LS, Bisaga I, Parikh P, Black M, et al. Mapping synergies and trade-offs between energy and the sustainable development goals. Nat Energy. 2018;3(1):10.

4. Pradhan P, Costa L, Rybski D, Lucht W, Kropp JP. A systematic study of sustainable development goal (SDG) interactions. Earth's Future. 2017;5(11): 1169-79.

5. Audretsch DB, Lehmann EE, Wright M. Technology transfer in a global economy. J Technol Transfer. 2014;39(3):301-12.

6. Murphy K, Kirkman GA, Seres S, Haites E. Technology transfer in the CDM: an updated analysis. Clim Pol. 2015;15(1):127-45.

7. Ockwell DG, Mallett A, editors. Low-carbon technology transfer: from rhetoric to reality. Abingdon: Routledge; 2012.

8. Wahab SA, Rose RC, Osman SIW. Defining the concepts of technology and technology transfer: A literature analysis. Int Bus Res. 2012;5(1):61.

9. Adams R, Jeanrenaud S, Bessant J, Denyer D, Overy P. Sustainability-oriented innovation: A systematic review. Int J Manag Rev. 2016;18(2):180-205.

10. Comin D, Hobijn B. An exploration of technology diffusion. Am Econ Rev. 2010;100(5):2031-59.

11. Mulder KF. Innovation for sustainable development: from environmental design to transition management. Sustain Sci. 2007:2(2):253-63.

12. Popp D, Hascic I, Medhi N. Technology and the diffusion of renewable energy. Energy Econ. 2011;33(4):648-62

13. IRENA. The power to change: solar and wind cost reduction potential to 2025: International renewable energy agency; 2016. Retrieved from: https:// www.irena.org/publications

14. IRENA. Rethinking energy 2017: accelerating the global energy transformation: International renewable energy agency-IRENA; 2017 Retrieved from: https://www.irena.org/-/media/Files/IRENA/Agency/ Publication/2017/IRENA REthinking Energy 2017.pdf

15. Lo K. A critical review of China's rapidly developing renewable energy and energy efficiency policies. Renew Sust Energ Rev. 2014;29:508-16.

16. Battistella C, De Toni AF, Pillon R. Inter-organisational technology/ knowledge transfer: a framework from critical literature review. J Technol Transfer. 2016;41(5):1195-234

17. Eleftheriadis IM, Anagnostopoulou EG. Identifying barriers in the diffusion of renewable energy sources. Energy Policy. 2015;80:153-64.
18. Lai PC. The literature review of technology adoption models and theories for the novelty technology. JISTEM-J Inf Syst Technol Manag. 2017;14(1):21-38

19. Li Y, Sui M. Literature analysis of innovation diffusion. Technol Invest. 2011; 2(03):155.

20. Marsh D, Sharman JC. Policy diffusion and policy transfer. Policy Stud. 2009; 30(3):269-88

21. Negro SO, Alkemade F, Hekkert MP. Why does renewable energy diffuse so slowly? A review of innovation system problems. Renew Sust Energ Rev. 2012:16(6):3836-46.

22. Shipan C, Volden C. Policy Diffusion: Seven Lessons for Scholars and Practitioners. Public Adm Rev. 2012;72(6):788-96.

23. Dolowitz D, Marsh D. Who learns what from whom? A review of the policy transfer literature. Polit Stud. 1996;44:343-57.

24. Dolowitz D, Marsh D. Learning from abroad: the role of policy transfer in contemporary policy-making. Governance. 2000;13(1):5-23.

25. REN Secretariat (2019). Renewable 2019. Global status report. Available at: https:// www.ren21.net/wp-content/uploads/2019/05/gsr_2019_full_report_en.pdf

26. Rockström J, Gaffney O, Rogelj J, Meinshausen M, Nakicenovic N, Schellnhuber H. A roadmap for rapid decarbonization. Science. 2017; 355(6331):1269-71.

27. Geels F, Schot J. Typology of sociotechnical transition pathways. Res Policy. 2007:36(3):399-417.

28. IRENA. Renewable power generation costs in 2018: International renewable energy agency-IRENA; 2018. Retrieved from: https://www.irena.org/-/media/ Files/IRENA/Agency/Publication/2019/May/IRENA_Renewable-PowerGenerations-Costs-in-2018.pdf

29. Geels F. Technological transitions as evolutionary reconfiguration processes: a multi-level perspective and a case-study. Res Policy. 2002;31(8):1257-74.

30. Geels F. The multi-level perspective on sustainability transitions: responses to seven criticisms. Environ Innov Soc Transit. 2011;1(1):24-40.

31. Carlsson B, Stankiewicz R. On the nature, function, and composition of technological systems. J Evol Econ. 1991;1(2):93-118.

32. Miller S. In: Zalta EN, editor. Social institutions, the Stanford Encyclopaedia of philosophy: Metaphysics research lab, Stanford University; 2014. https:// plato.stanford.edu/entries/social-institutions/.

33. Hassel A, Jansen J, Egenhofer C, Xu Z, De Jong J. Improving the market for flexibility in the electricity sector: report of a CEPS task force. Centre for European Policy Studies: Brussels; 2017

34. Hiroux C, Saguan M. Large-scale wind power in European electricity markets: time for revisiting support schemes and market designs? Energy Policy. 2010;38(7):3135-45.

35. Hegger D, Vliet JV, Vliet BJMV. Niche management and its contribution to regime change: the case of innovation in sanitation. Tech Anal Strat Manag 2007:19(6):729-46.

36. Schot J, Geels F. Strategic niche management and sustainable innovation journeys: theory, findings, research agenda, and policy. Tech Anal Strat Manag. 2008;20(5):537-54.

37. Grubb M, McDowall W, Drummond P. On order and complexity in innovations systems: Conceptual frameworks for policy mixes in sustainability transitions. Energy Res Soc Sci. 2017;33:21-34.

38. North D. Institutions, Institutional Change and Economic Performance. Cambridge: Cambridge University Press; 1990.

39. Rose R. What is lesson-drawing? J Public Policy. 1991;11(1):3-30.

40. Bennett C. What is policy convergence and what causes it? Br J Polit Sci. 1991;21(2):215-33.

41. Clark J. Policy diffusion and program scope: research directions. Publius J Fed. 1985:15(4):61-70

42. Haas P. Do regimes matter? Epistemic communities and Mediterranean pollution control. Int Organ. 1989:43(3):377-403.

43. Majone G. Cross-National Sources of Regulatory Policymaking in Europe and the United States. J Public Policy. 1991:11(1):79-106.

44. Jann W, Wegrich K. Theories of the policy cycle. In: Fischer F, Miller GJ, editors. Handbook of public policy analysis. Boca Raton: Taylor \& Francis; 2007. p. 43-63.

45. World Bank, Thailand / data, 2018. Retrieved from: https://data.worldbank. org/country/thailand. Accessed 27 Sept 2018.

46. IEA (2016). Partner country series - Thailand electricity security assessment International energy agency. Retrieved from: https:/www.iea.org/publications/

47. NESDB. The twelfth National Economic and social development plan: Office of the National Economic Development Board; 2016. 
48. World Bank, Access to electricity, rural (\% of rural population) | data, 2018. Retrieved from: https://data.worldbank.org/indicator/. Accessed 27 Sept 2018.

49. Gamio P. Personal communication with A. Bruno, April 2016; 2016.

50. USTR. The United States - Peru trade promotion agreement. Final text: Office of the United States Trade Representative; 2018. Available: https:// ustr.gov/trade-agreements/free-trade-agreements/peru-tpa/final-text. Accessed 27 Sept 2018

51. EPPO. Energy Statistic (2017). Available at: http://www.eppo.go.th/index. php/en/en-energystatistics/indicators.

52. IRENA. Renewable energy auctions in developing countries: International Renewable Energy Agency-IRENA; 2013. Retrieved from: https://www.irena. org/publications

53. Sarochawikasit, R. (2007). Renewable Energy Development and Environment in Thailand. Available at: http://www.jst.go.jp/astf/document2/en_22doc.pdf.

54. UN. (2011). Thailand Energy Report. Available at: http://www.un.org/esa/ agenda21/natlinfo/countr/thai/energy.pdf

55. Bijoor S, Greacen C. Citizen-oriented power sector reform in Thailand; 2007. p. 1-22. Available at: https://www.academia.edu/1555157/CITIZENORIENTED_POWER_SECTOR_REFORM_IN_THAILAND

56. Tongsopit S, Greacen C. Thailand's renewable energy policy: FiTs and opportunities for international support; 2012. p. 1-24. Available at: http://www. palangthai.org/docs/ThailandFiTtongsopit\&greacen.pdf. Accessed 1 Dec 2016

57. Tongsopit S, Greacen C. An assessment of Thailand's feed-in tariff program in: renewable energy. Elsevier Ltd. 2013;60:439-45.

58. Hoberg G. Sleeping with an elephant: the American influence on Canadian environmental regulation. J Public Policy. 1991:11(1):107-31.

59. Coronado J. Personal communication with A. Bruno. 2016;2016.

60. Bößner, S. (2016). Turning energy around: coal and the German Energiewende. SEl Discussion Brief. Available at: https://www.sei.org/ publications/coal-and-energiewende/

61. Bulmer S, Padgett S. Policy Transfer in the European Union: An Institutionalist Perspective. Br J Polit Sci. 2005;35(1):103-26.

62. Mendoza E. Personal communication with A. Bruno. 2016;(April 2016).

63. MoEN (Thailand). (2007). Energy Industry Act. Available at: http://www. thailawforum.com/laws/Energy

64. Siteur, J. (2012). Rapid deployment of industrial biogas in Thailand: factors of success, institute for industrial productivity. Available at: http://www. iipnetwork.org/IIP-10.BiogasCaseStudy.Pdf.

65. Gilardi F. Transnational diffusion: norms, ideas, and policies. In: Carlsnaes W, et al., editors. Handbook of international relations. 1st ed. Thousand Oaks: SAGE Publications; 2012. p. 453-77.

66. Global Energy Transfer Feed-in Tariff- GET FiT (2017). Annual Report, 2017.

\section{Publisher's Note}

Springer Nature remains neutral with regard to jurisdictional claims in published maps and institutional affiliations.

Ready to submit your research? Choose BMC and benefit from:

- fast, convenient online submission

- thorough peer review by experienced researchers in your field

- rapid publication on acceptance

- support for research data, including large and complex data types

- gold Open Access which fosters wider collaboration and increased citations

- maximum visibility for your research: over $100 \mathrm{M}$ website views per year

At $\mathrm{BMC}$, research is always in progress.

Learn more biomedcentral.com/submissions 